\title{
Karbontetraklorür İle Karaciğer Hasarı Oluşturulan Ratlarda Tribulus terrestris'in Antihiperlipidemik Etkisinin Araştırılması
}

\author{
Zafer ÇAMBAY $^{1 *}$ Naci Ömer ALAYUNT ${ }^{2}$ \\ ${ }^{1}$ Fırat Üniversitesi Sağllk Hizmetleri Meslek Yüksek Okulu, 23200, Elazığ \\ ${ }^{2}$ Uşak Üniversitesi Banaz Meslek Yüksek Okulu, 64520, Ușak \\ (ORCID: 0000-0002-1170-7525) (ORCID: 0000-0003-2215-0934)
}

\begin{abstract}
$\ddot{\mathbf{O} z}$
$\mathrm{Bu}$ araştırmada, karbon tetraklorür ile deneysel olarak oluşturulan hepatotoksisite ile ratların kan lipid parametrelerine karşı güçlü antioksidan etkisine sahip olan Tribulus terrestris'in koruyucu etkinliğinin ve antihiperlipidemik rolünün araştırılması amaçlanmıştır. Çalışmada 35 adet 8-12 haftalık Wistar-Albino erkek rat kullanılmıştır. Çalışma beş grupa ayrılıp her grupta 7 adet ratla başlanmışı̧ı. Kontrol grubundaki ratlar 14 gün standart yemle beslenmiştir. Diğer gruplardaki ratlara standart yem ve 14 gün boyunca $0,8 \mathrm{ml} / \mathrm{kg}$ CCI4 intraperitoneal olarak uygulanmıştır. 3,4 ve 5 gruplarda ki ratlara ise intraperitoneal olarak uygulanan $0,8 \mathrm{ml} / \mathrm{kg}$ CCI4'e sonra 8 hafta boyunca Tribulus terrestris bitki ekstraktı verilmiştir. Deney sonunda tüm sıçanlar uygun ortam ve şartlarda dekapite edilerek ve çalışmanın sonuçlarının inceleneceği parametreler için uygun kan örnekleri alınmıştır. Alınan kan örnekleri jelli düz biyokimya tüplerine alınacak, 4000 rpm'de 5-10 dakika santrifüj edilerek serum elde edilmiştir. Elde edilen serumlar otoanalizör yardımıyla lipid parametreleri belirlenmiştir. Karbontetraklorür ile karaciğer hasarı oluşturan grup ile kontrol grubu lipid parametreleri total kolesterol, trigliserit, düşük dansiteli lipoprotein kolesterol (LDL-K), çok düşük dansiteli lipoprotein kolesterol (VLDL-K) ve yüksek dansiteli lipoprotein kolesterol (HDL-K) değerlerinin arasında istatiksel bir fark olduğu saptand $(\mathrm{P}<0.05) .2 \mathrm{~g} / \mathrm{kg}$ Tribulus terrestris' in verilen $\mathrm{CCl}_{4}$ uygulanmış 5 . gruptaki lipid parametreleri ile kontrol grubu arasında anlamlı bir fark saptanmadı ( $\mathrm{P}>0.05)$. CCI4'ün neden olduğu oksidatif stres ve lipit peroksidasyonu sonucu oluşturulan hiperlipidemiye karşı Tribulus Terrestris' in bitkisinin önemli düzeyde azaltıcı etkisinin olduğu belirlenmiştir.
\end{abstract}

Anahtar kelimeler: $\mathrm{CCl}_{4}$, Tribulus Terrestris, antihiperlipidemi

\section{Examination of the Antihyperlipidemic Effect of Tribulus terrestris in Liver- Damaged Rats with Carbontetrachloride}

\begin{abstract}
The aim of this study was to investigate the protective effect and antihyperlipidemic role of Tribulus Terrestris, a potent antioxidant effect of hepatotoxicity in experimental rats on carbon tetrachloride and lipid parameters. 35 Wistar-Albino male rats aged 8-12 weeks were used in the study. Rats were divided into 5 groups of 7 animals per group and rats in the control group were fed standard food for 14 days. In groups 3, 4 and 5 rats, Tribulus terrestris plant extracts were given 8 weeks after intraperitoneal administration of $0.8 \mathrm{ml} / \mathrm{kg}$ CCI4. All rats were cut in the appropriate medium and blood samples were taken for the parameters to be monitored. Blood samples from were taken with glandular biochemical tubes and centrifuged at $4000 \mathrm{rpm}$ for 5-10 minutes to obtain serum. Lipid parameters were determined using an autoanalyzer. The lipid parameters of carbon tetrachloride and liver damage group and control group were found between total cholesterol, triglyceride, low-density lipoprotein cholesterol, very low-density lipoprotein cholesterol and high-density lipoprotein cholesterol significantly $(\mathrm{P}<0.05)$. There was no significant difference between the control group and the 5th cycle lipid parameters of CCl4 given $2 \mathrm{~g} / \mathrm{kg}$ Tribulus terrestris $(\mathrm{P}>0.05)$. Oxidative stress and lipid peroxidation caused by CCI4 have been identified as an important inhibitory effect of Tribulus terrestris in against liver damage and hyperlipidemia.
\end{abstract}

Keywords: CCl4, Tribulus terrestris, antihyperlipidem

"Sorumlu yazar: zcambay@firat.edu.tr

Geliş Tarihi: 20.02.2019, Kabul Tarihi: 01.07.2019 


\section{Giriş}

Karbontetraklorür $\left(\mathrm{CCl}_{4}\right)$ hepatotoksik etkisi bilinen ve bu konuda birçok araştırma yapılmış olan kimyasal bir üründür. $\mathrm{CCl}_{4}$ ile in vitro şartlarda oluşturulan zararda etkilenen birinci derecede karaciğer olsa da bu toksikasyon sonucu birçok organ ve sistem doğrudan ve dolaylı olarak etkilenmektedir [1-3]. CCl4'un düşük dozlarda uzun süreli uygulanması sonucu karaciğer hücrelerinde lipid dejenerasyonuna, doz arttıkça ise karaciğer hücrelerinin nekrozuna, paranşimde kanamalara neden olduğu gösterilmektedir [4-6]. $\mathrm{CCl}_{4}$ ile oluşturulan toksikasyonda hücre hasarı, lipid peroksidasyonundaki artışla doğru orantılıdır ve bu toksik etkinin, serbest radikallere dönüşümü ile olduğu belirlenmiştir. Son zamanlarda $\mathrm{CCI}_{4}$ 'ün lipid peroksidasyonunu artırması ve oksidatif stres meydana getirmesi sonucu antioksidanlar ve oksidanlar arasında dengenin bozulmasına neden olmaktadır ve artan oksidatif stress ile karaciğer hasarıyla ilişkili olduğunu bildirmişlerdir [7, 8]. Karaciğerin, CCl4'ün indüklediği hasara karşı korunmasında ve tedavisinde antioksidanların kullanılması yararlı olabilir. Böylelikle fitoterapide kullanılan birçok ilacın, toksik etkilerinin az olması ucuz ve kolay bulunabilirliği dolayısı ile çeşitli kimyasallarla oluşturulan karaciğer hasarına karşı hayvan modellerinde yapılan deneysel araştırmalar son yıllarda artmıştır [9].

Çalışma konumuz olarak seçilen Tribulus terrestris L. türü Zygophyllaceae familyasından Tribulus cinsine bağlıdır. Ülkemizde ise 5 cinsi ve 6 türü yetişmektedir. Tribulus cinsinin ülkemizde yetişen tek türü Tribulus terrestris'dir. T. terrestris'in içerisinde bulunan etken maddeler pek çok hastalık için tedavi edici özelliktedir. Yurdumuzda yaygın olarak yetişen bu bitki üzerinde Türkiye'de yapılmış yeterince çalışma yoktur. Genel olarak afrodizyak, antimikrobiyal, diüretik, antihelmintik, antienflamatuar, antihipertansif, kardiyotonik, vazodilatör, antikanser, karaciğer koruyucu, kolesterol düşürücü, antihiperlipidemik antidiyabetik ve analjezik etkilere sahiptir [10]. Bitkinin belirtilen kullanımları nedeniyle herhangi bir yan etkisinin bulunmayışı da bitkiye olan ilgiyi arttırmaktadır. Tribulus terrestris'in, saponin (protodiosin, furostanol), glikozit, flavonoit, alkaloit, reçine, tanen, şeker, sterol ve uçucu yă olmak üzere birkaç farklı etken madde grubu içerir. Son günlerde yapılan çalışmalarla Tribulus terrestris'den 20'nin üzerinde saponin tanımlanmıştır. Tribulus terrestris' in meyvelerinden karaciğer koruyucu özelliği olduğu bilinen yeni Tribulusamid A ve B lignanamidleri izole edilmiştir [11]. Karaciğer hasarına karşı Tribulus terrestris'in bitkisinin etkisi konusunda pek araştırma yapılmadığ 1 saptanmıştır.

Bu çalışma, ratlarda oksidatif stres meydana getiren ve karaciğere zararlı etkisi bilinen kimyasal madde $\mathrm{CCI}_{4}$ 'e karşı, Tribulus terrestris 'in antihiperlipidemik etkisi üzerine etkileri araştırılmıştır.

\section{Materyal ve Metot}

Çalışmada 35 adet 8-12 haftalık Wistar-Albino erkek rat kullanılmıştır. Ratlar her grupta 7 adet olmak üzere beş gruba ayrılmıştır. Kontrol grubundaki ratlar 14 gün standart yemle beslenmiştir. 2. gruptaki ratlara standart yem ve 14 gün boyunca $0,8 \mathrm{ml} / \mathrm{kg}$ CCI4 intraperitoneal olarak uygulanmıştır. 3,4 ve 5 gruplarda ki ratlara ise intraperitoneal iki hafta boyunca $0,8 \mathrm{ml} / \mathrm{kg}$ CCI4'e ilave uygulamasindan sonra 8 hafta boyunca Tribulus terrestris bitki ekstraktı verilmiştir. Çalışmanın başında ve sonunda rat ağırlıkları ölçülmüştür. Deney sonunda (Grup 1 ve 2 deney başlangıcından 2 hafta sonra, Grup 3, 4 ve 5 ise 10 hafta sonra) tüm sıçanlar uygun ortam ve şartlarda dekapite edilerek ve çalışmanın sonuçlarının inceleneceği parametreler için uygun kan örnekleri alınmıştır. Alınan kan örnekleri jelli düz biyokimya tüplerine alınacak, 4000 rpm'de 5-10 dakika santrifüj edilerek serum elde edilmiştir. Fırat Üniversitesi Hayvan Deneyleri Yerel Etik Kurulu (31.03.2017 / 2017/07 karar no:81 Protokol 2017-39) onay1 alınarak; etik kurallarına uygun olarak yapılmıştır. Lipit parametreleri olan total kolesterol, trigliserit, LDL-K, VLDL-K ve HDL-K parametreleri için uygun kitler kullanılarak spektrofotometrik olarak Siemens Advia 2400 marka otoanalizör cihazı kullanılarak ölçülmüştür.

Çalışma boyunca hayvanlara olan müdahaleler Fırat Üniversitesi Deney Hayvanları Yerel Etik Kurulu tarafından saptanan ilkelere göre yapıldı. Hayvanların bakımı Fırat Üniversitesi Deney Hayvanları Uygulama ve Araştırma Merkezinde gerçekleşecektir. Sunulan araştırmada karbontetraklorür toksikasyonu oluşturmak amacıyla kullanılan karbontetraklorür Merck firmasından temin edilecektir.

Rasgele örnekleme metodu ile her biri 7 sıçandan oluşmak üzere toplam beş grup oluşturulacaktır.

- Grup 1: Kontrol grubu 
- Grup 2: CCl4 grubu

- Grup 3: $\mathrm{CCl} 4+0,5 \mathrm{~g} / \mathrm{kg}$ Tribulus terrestris

- Grup 4: $\mathrm{CCl} 4+1 \mathrm{~g} / \mathrm{kg}$ Tribulus terrestris

- Grup 5: $\mathrm{CCl} 4+2 \mathrm{~g} / \mathrm{kg}$ Tribulus terrestris

\subsection{Tribulus terrestris uygulamaları}

Tribulus terrestris ekstratı su ile çözünerek hazırlandı. Çalışma gruplarından Tribulus terrestris ekstratı verilecek gruba (3,4 ve 5 Grup), sırasıyla $0.5,1,2 \mathrm{~g} / \mathrm{kg}$ vücut ağırlığı dozunda bitki ekstratı oral yoldan verildi.

\section{2. $\mathrm{CCl}_{4}$ uygulamaları}

Kontrol grubu dışındaki tüm ratlar 14 gün boyunca standart yeme ilave her gün $0,8 \mathrm{ml} / \mathrm{kg} \mathrm{CCI}_{4}, 0,8$ $\mathrm{ml} / \mathrm{kg}$ sıv1 yağ içinde çözülerek intraperitoneal olarak uygulandı.

\section{3. Çalış̧manın sonlandırılması}

Tribulus terrestris uygulamalarından 24 saat sonra tüm hayvanlardan sodyum pentobarbital (pentobarbital sodium, $40 \mathrm{mg} / \mathrm{kg}$, i.p.) anestezisi altında [12] tetkikler için gerekli kan örnekleri alınarak, labaratuvar analizleri için hazırlandı. Bütün veriler ortalama \pm standart hata $(\mathrm{SH})$ şeklinde tanımlanacak, verilerin değerlendirilmesinde tek yönlü varyans analizi (ANOVA) kullanıldı.

Elde edilen veriler SPSS-22 programında One Way ANOVA testi uygulanarak istatistikleri hesaplanmıştır.

\section{Bulgular ve Tartışma}

Tablo1'de deney hayvanlarının kan serumundan alınan örneklerde lipid parametrelerinin sonuçları gösterilmiştir. $\mathrm{CCl}_{4}+2 \mathrm{~g} / \mathrm{kg}$ Tribulus terrestris verilen grup ile $\mathrm{CCl}_{4}$ grubu arasında total kolesterol LDL-kolesterol, VLDL-kolesterol seviyelerinde önemli bir artışı, HDL-kolesterol, seviyelerinde ise anlamlı bir azalma olduğu görüldü $(\mathrm{P}<0.05) . \mathrm{CCl}_{4}$ gruplarına Tribulus terrestris uygulamasıyla artmış trigliserid düzeylerini kontrol grubu değerlerine yaklaştırdığ 1 5.grup ile kontrol grubu arasında fark olmadığ görülmüştür $(\mathrm{P}>0.05)$.

Tablo 1. Deney hayvanlarının ortalama lipit parametreleri düzeyleri

\begin{tabular}{|c|c|c|c|c|c|}
\hline GRUPLAR & $\begin{array}{c}\text { Kolesterol } \\
(\mathbf{m g} / \mathbf{d l})\end{array}$ & $\begin{array}{c}\text { Trigliserid } \\
(\mathbf{m g} / \mathbf{d l})\end{array}$ & $\begin{array}{c}\text { LDL-K } \\
(\mathbf{m g} / \mathbf{d l})\end{array}$ & $\begin{array}{c}\text { HDL-K } \\
(\mathbf{m g} / \mathbf{d l})\end{array}$ & $\begin{array}{c}\text { VLDL-K } \\
(\mathbf{m g} / \mathbf{d l})\end{array}$ \\
\hline Kontrol & $96.48 \pm 6.32^{\mathrm{b}}$ & $88.36 \pm 6.32^{\mathrm{b}}$ & $56.34 \pm 6.82^{\mathrm{b}}$ & $52.60 \pm 6.24^{\mathrm{b}}$ & $18.24 \pm 3.02^{\mathrm{b}}$ \\
\hline CCI $_{4}$ & $279.86 \pm 5.22^{\mathrm{a}}$ & $148.52 \pm 7.54^{\mathrm{a}}$ & $218.56 \pm 4.38^{\mathrm{a}}$ & $34.68 \pm 8.28^{\mathrm{a}}$ & $34.84 \pm 6.28^{\mathrm{a}}$ \\
\hline Grup 3 & $202.20 \pm 3.62$ & $128.32 \pm 6.36$ & $142.36 \pm 8.48$ & $40.12 \pm 3.24$ & $31.24 \pm 2.66$ \\
\hline Grup 4 & $168.38 \pm 3.58$ & $120.36 \pm 2.38$ & $116.68 \pm 4.42$ & $43.84 \pm 6.22$ & $27.26 \pm 4.46$ \\
\hline Grup 5 & $109.88 \pm 7.48^{\mathrm{b}}$ & $102.36 \pm 8.02^{\mathrm{b}}$ & $74.92 \pm 6.34^{\mathrm{b}}$ & $48.32 \pm 3.02^{\mathrm{b}}$ & $23.32 \pm 5.56^{\mathrm{b}}$ \\
\hline
\end{tabular}




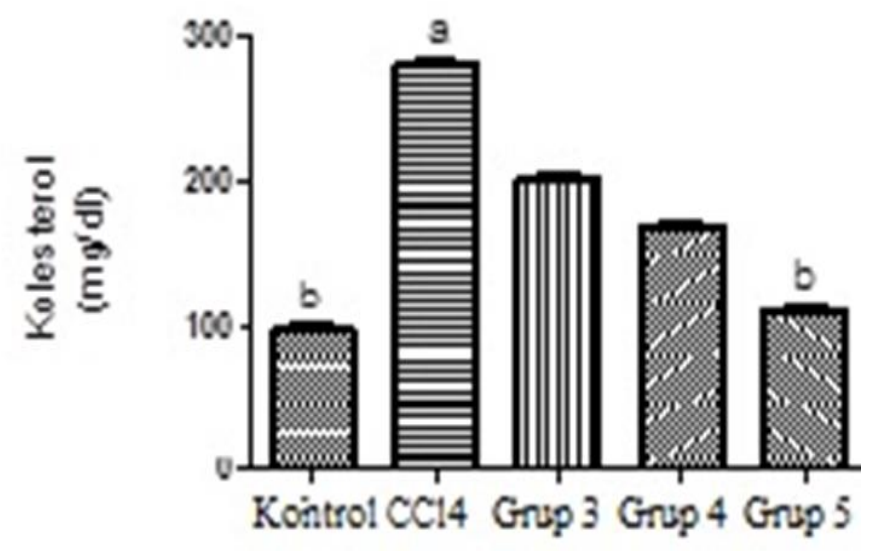

Şekil 1. Gruplardaki kolesterol grafiği

Farklı harfler gruplar arasındaki farklılı̆̆ 1 göstermektedir. ${ }^{\text {a ile b }} \mathrm{p}<0,05$

$\mathrm{CCl}_{4}+2 \mathrm{~g} / \mathrm{kg}$ Tribulus terrestris verilen grup ile $\mathrm{CCl}_{4}$ grubu arasında total kolesterol değerleri (Şekil 1) arasında anlamlı olarak düştüğü $(\mathrm{P}<0.05)$ kontrol grubu ile 5.grup arasında fark olmadığ1 gözlenmiştir.

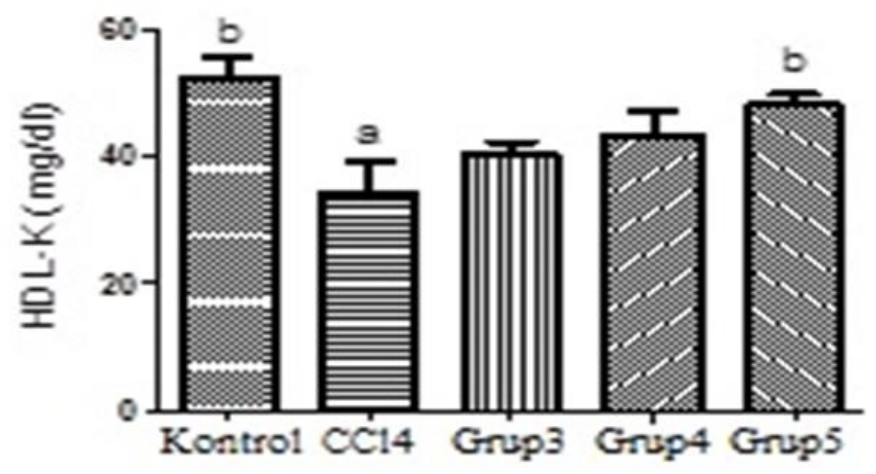

Şekil 2. Gruplardaki HDL-K grafiği

Farklı harfler gruplar arasındaki farkl1lığı göstermektedir. ${ }^{\text {a ile }}{ }^{\mathrm{b}} \mathrm{p}<0,05$

HDL-kolesterol değerleri kontrol grubunda CCl4 grubuna göre yüksek çıktığ $1(\mathrm{P}<0.05)$ (Şekil 2) kontrol grubu ile 5.grup arasında fark olmadığ saptanmıştır. $\mathrm{CCl}_{4}$ grubu ve kontrol grubu LDLkolesterol değerleri arasında istatiksel fark olduğu (Şekil 3) görülmüştür $(\mathrm{P}<0.05)$.

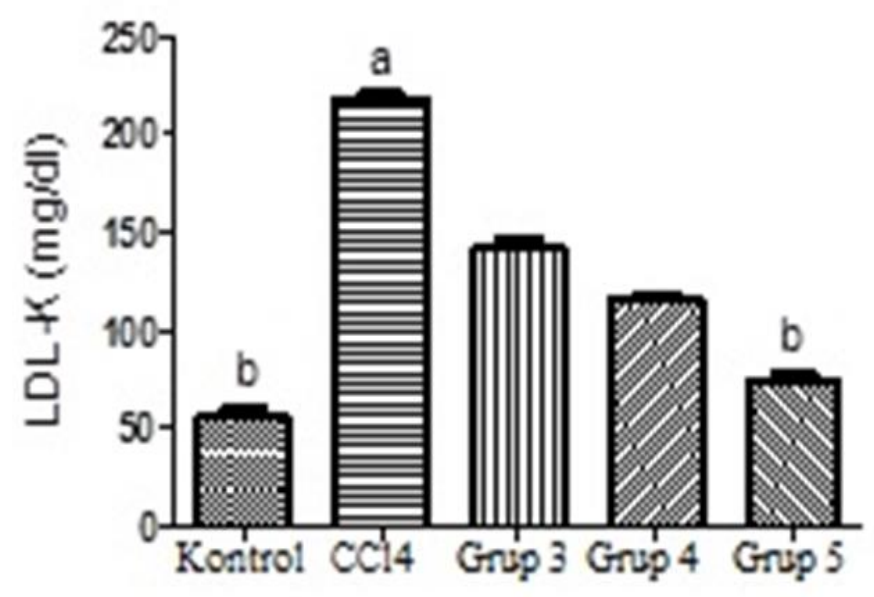

Şekil 3. Gruplardaki LDL-K grafiği

Farklı harfler gruplar arasındaki farklılığı göstermektedir. ${ }^{\text {a ile b }} \mathrm{p}<0,05$ 


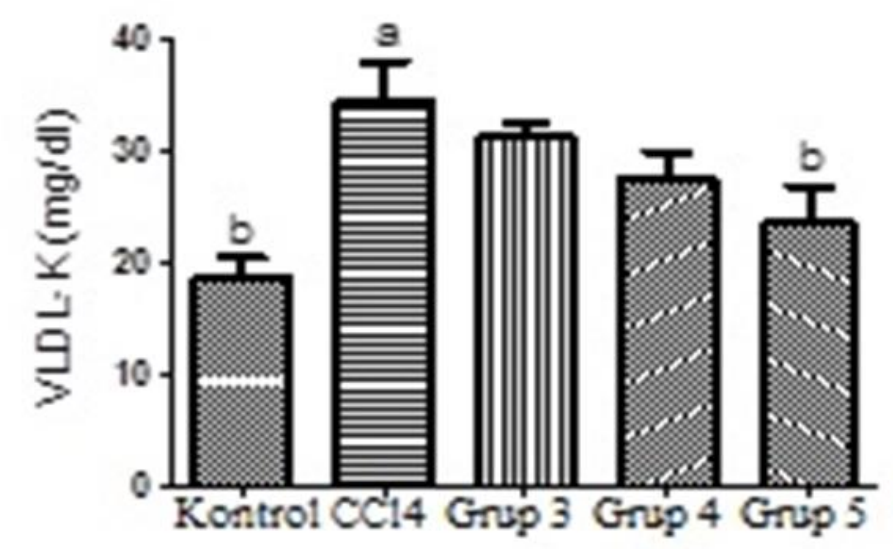

Şekil 4. Gruplardaki VLDL-K grafiği

Farklı harfler gruplar arasındaki farklılığı göstermektedir. ${ }^{\text {a ile b }} \mathrm{p}<0,05$

Kontrol grubu ve 5.gruba göre $\mathrm{CCl}_{4}$ grubunda VLDL-kolesterol düzeylerinde istatistiksel olarak önemli bir artışın $(\mathrm{P}<0.05)$ olduğu saptanmıştır (Şekil 4).

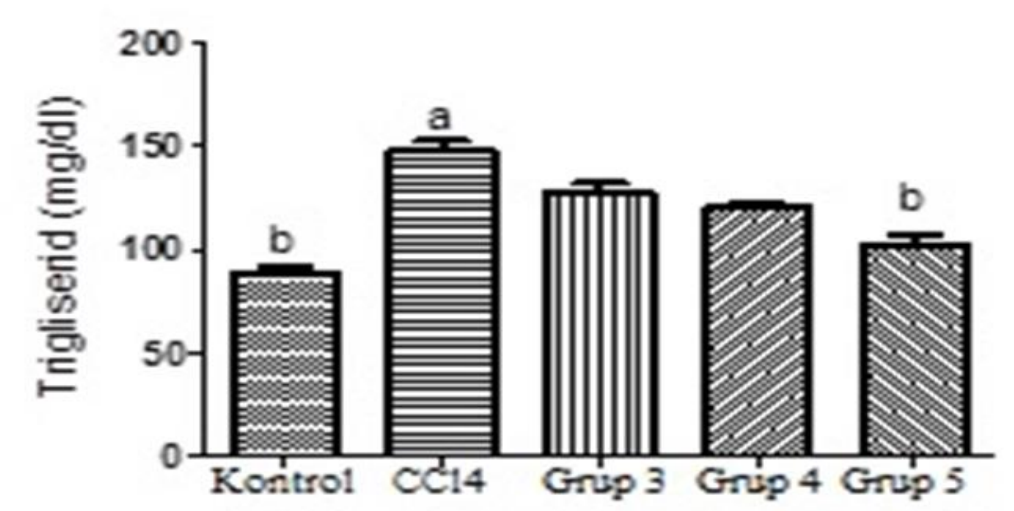

Şekil 3. Gruplardaki trigliserid grafiği

Farklı harfler gruplar arasındaki farkl1lığı göstermektedir. ${ }^{\text {a ile }} \mathrm{b} p<0,05$

Trigliserid değerlerinde ise Tribulus terrestris uygulaması arttıkça sonuçlarda düşüş gözlenmiştir (Şekil 5). $\mathrm{CCl}_{4}$ grubundaki değer çok yüksek çıkmıştır. 5.grupta ise anlamlı olarak bu değerin düştüğü saptanmıştır $(\mathrm{P}<0.05)$.

$\mathrm{CCl}_{4}$ hepatositlere etki ederek, sitokrom $\mathrm{P} 450$ enzim sistemi ile toksik yapıda triklorometil $\left(\mathrm{CCl}_{3}\right)$ ve triklorometil peroksil $\left(\mathrm{CCl}_{3} \mathrm{O}_{2}\right)$ serbest radikallere dönüşmesi ile hücre zarında bulunan doymamış yağ asitleri ile etkileşime girmesi sonucu karaciğer hasarını meydana getirdiği belirtilmektedir $[13,14]$.

Yapılan birçok çalışmada, karaciğer hastalıklarında oksidatif stresin arttığı dolayısıyla karaciğer hasarı ve fibrozu arasında ilişki olduğu gösterilmiştir [15-17]. Oksidatif stres antioksidan mekanizma üzerindeki olumsuz etkilerine bağlı olarak lipid peroksidasyonunu artırıp karaciğerde fibrozise neden olabilmektedir [17]. Karbon tetraklorüre maruz kalan sıçanların karaciğerleri morfolojik olarak incelendiğinde; yağlanma, hidrofik distrofi, hepatosit sitoplazmasında yıkıcı değişimler ve hepatositlerin ağır nekrozu gibi çok önemli değişimlerin olduğu ifade edilmiştir [18].

Tribulus terrestris'deki saponinlerin hipoglisemik etkisini incelemek amaçlı bir çalışma yapılmıştır. Alloksan kullanılarak diyabetik sıçanlar elde edilmiştir. Fenformin tabletleri de pozitif kontrol için kullanılmışır ve serumdaki glikoz, trigliserit, SOD ve kolesterol seviyeleri ölçülmüsstür. Çalışma sonucunda Tribulus terrestris saponini verilen ratların kan şekerinde belirgin bir düşüş gözlenmiştir. Saponinler serumdaki kolesterol ve trigliserid seviyelerini de düşürmüştür. Serumdaki SOD seviyesinde ise artış gözlenmiştir. Sonuç olarak Tribulus terrestris'deki saponinler kan şekerini belirgin şekilde düşürmüştür. Bu literatüre göre sonuçlarımız uygunluk göstermekte kolesterol ve trigliserid düzeylerindeki artışın Tribulus terrestris bitkisi verilmesi ile düştüğü gözlenmiştir [19]. 
Tribulus terrestris'deki saponinlerin antihiperlipidemik etkisini anlamak amaçlı bir çalışma yapılmıştır. Diyete tabi tutulan hiperlipidemik sıçanlarda Tribulus terrestris'de bulunan saponinlerin koruyucu ve terapötik etkisi üzerinde çalışılmıştır. Saponin verilmesinden sonra sıçanların serum toplam kolesterolü (TC) ve kötü kolesterolü (LDL) ile karaciğer toplam kolesterolü ve trigliserit seviyeleri düşük çıkarken karaciğerdeki SOD aktivitelerinde artı̧̧ gözlenmiştir. Çalışmalar sonucunda saponin tedavisinin karaciğer ve serumdaki toplam kolesterol seviyesinde belirgin bir düşüşe sebep olduğu belirlenmiştir Sunulan çalışmada da bu çalışmanın bulgularıyla uyumlu olarak karaciğer hasarı ile artan lipid parametreleri Tribulus terrestris uygulaması kolesterol, LDL ve trigliserid seviyelerini düşürmesi sonuçları destekler niteliktedir [20]. Tribulus terrestris bitkisinin sulu ve metanolik ekstraktları ile in vitro şartlarda hipertansif farelerle yaptıkları çalışmada hipertansiyona karşı vazo dilatatör etkisi ile anlamlı oranlarda tansiyon düşürücü etkisi olduğunu bildirmişlerdir [21].

Tribulus terrestris ve $T$. alatus'un hipoglisemik ve hipolipidemik özellikleri üzerinde karşılaştırmalı bir çalışmalar yapılmıştır. Buna göre streptozotocin'in sebep oluğu hipoglisemik sıçanlarda, T.alatus ve T. terrestris alkol ekstresinin verildiği sıçanların, uygulamadan 2, 4 ve 6 saat sonra kan şekeri seviyelerinde, verilmeyen sıçanlara kıyasla önemli bir düşüş gözlenmiştir. T. terrestris ekstresi verilen diyabetik sıçanlarda TAG, TC ve LDL-c seviyelerinde verilmeyenlere karşılık önemli düşüş gözlenmiştir. TC ve LDL-c seviyeleri kontrol grubuna eşit ve HDL-c seviyesi ise kontrol grubundan önemli ölçüde yüksek çıkmıştır. [22]. Bu bulgularla yaptığımız araştırmanın sonuçları kismen de olsa uyum arz etmektedir.

Beyaz Plymouth Rock- cüce horozların içme suyuna eklenen Tribulus terrestris ekstresinin semen kalitesini ve kan serumu toplam kolesterol içeriğini nasıl etkilediğini araştırmak için bir çalışma yapılmıştır. Deney horozlarında serum toplam kolesterol içeriği kontrol grubuna nazaran $\% 9.24$ daha az $(\mathrm{P}>0.05)$ çıkmıştır. Araştırılan parametreler üzerinde Tribulus terrestris'in artetkisi sekiz hafta boyunca korunmuştur [23]. Yüksek kolesterollü bir diyette tavşanların aort damarında aterosklerotik lezyonlar geliştirmede lipid profili ve endotelyal yapı üzerinde Tribulus terrestris ekstresinin etkisi araştırılmıştır. Elde edilen veriler Tribulus terrestris' in diyete bağlı alımının belirgin şekilde serum lipid profillerini düşürebileceğini, endotelyal selüler yüzey hasarı ve rüptüreyi (rüptür: bir organ ya da dokunun yırtılması) azaltabileceğini ve hiperlipidemiden kaynaklanan endotelyal disfonksiyonu kısmen onarabileceğini göstermiştir [24]. Diyabette Tribulus terrestris'in koruyucu etkisini incelemek amaçl1 başka bir çalışma yapılmıştır. Bu çalışmada diabetes mellitus (DM)'da Tribulus terrestris 'in koruyucu etkilerini araştırmaktır. Diyabetin, patojenezine yol açan reaktif oksijen türlerinin (ROS) seviyesini arttırdığı bilinmektedir. Histopatolojik muayene bitki ile tedavi edilen farelerde önemli karaciğer iyileşmesi göstermiştir. Bu araştırma STZ kaynaklı diyabetik fareler için Tribulus terrestris'in koruyucu etkisinin oksidatif stresi engelleyerek yöneltilebileceğini ileri sürmektedir [25]. Kontrol ve selüloz ile karıştırılan düşük ve yüksek doz Tribulus terestris gruplarının kontrol grubuna oranla daha düşük plazma kolesterol düzeyine sahip oldukları bildirilmiştir [27]. Ratlarda akut [28, 29] ve kronik [30, 31] olarak farklı dozlarda $\mathrm{CCl}_{4}$ 'ün oluşturduğu karaciğer hasarından dolayı kan serumundaki kolesterol ve trigliserid düzeylerini artırdığ 1 bildirilmiştir. Dolayısıyla kan serumundaki lipid parametrelerindeki artışın, $\mathrm{CCl}_{4}$ uygulamasıyla trigliserid artmasına neden olması [32] ve karaciğer hücre hasarına bağlı fazla miktarda dolaşım sistemine katıldığı düşünülmektedir [28, 33]. Ratlarda $\mathrm{CCl}_{4}$ sonucu oluşturulmuş hepatotoksisiteye karşı kolesterol düzeyleri ile ilgili az sayıda çalışmalara ulaşılabilmiştir [28, 31]. Khan ve ark. [32], bir ay boyunca haftada iki defa $3 \mathrm{ml} / \mathrm{kg}$, Al-Assaf ve arkadaşları [28] tek doz $1.25 \mathrm{ml} / \mathrm{kg}$ CCl4 uygulaması LDL-kolesterol düzeyini artmasına, HDL-kolesterol düzeyinin azalmasına sebep olmuştur. Yapılan çalışmada da bu araştırmacıların $[28,33]$ sonuçlarına göre uygun şekilde yaptığımız araştırmada olduğu gibi uygulanan CCl4'e bağlı olarak karaciğer hasarında saptanan serum LDLkolesterol düzeylerinde artışlar saptanmıştır.

\section{Sonuç ve Öneriler}

Tribulus terrestris etkisi ile ilgili yapılan birçok araştırma sonuçları bizim çalışmamızda gözlenen bulgulara benzer bulgular göstermiştir. Ratlarda $\mathrm{CCl}_{4}$ ile oluşturulan karaciğer hasarına karşı Tribulus terrestris bitkisinin etkisinin belirlenmesine yönelik çalışma olmadığ 1 antihiperlipidemik etkisinin saptandığı belirlenmiştir. Sonuç olarak; Tribulus terrestris'in ekstraktının uygun dozlarda ve zamanlarda kullanılarak etkilerinin belirlenmesine yönelik yeni araştırmalara ihtiyaç olduğu kanaatine varılmıştır. 


\section{Kaynaklar}

[1] Çınar A., Yörük M., Meral İ., Kiliçalp D., Koç A., Ertekin A. 1999. The effects of carbon tetrachloride $\left(\mathrm{CCl}_{4}\right)$ induced experimental acute and chronic intoxication on hystological structure of liver and some hematological values and electrocardiogram in Rabbits. Turk J Vet Anim Sci, 23: 235-242.

[2] Karakuş A., Değer Y., Yıldırım S. 2016. Protective effect of Silybum marianum and Taraxacum officinale extracts against oxidative kidney injuries induced by carbon tetrachloride in rats. Ren Fail., 39: 1-6.

[3] Mukhopadhyay P., Mukherjee S., Ahsan K., Bagchi A., Pacher P., Das D.K. 2010. Restoration of altered microRNA expression in the ischemic heart with Resveratrol. PLoS One, 23:5 (12): e15705.

[4] Wang C., Fan R.Q., Zhang Y.X., Nie H., Li K. 2016. Naringenin protects against isoniazid-and rifampicin-induced apoptosis in hepatic injury. World J Gastroenterol, 22: 9775-9783.

[5] Bhuvaneswari R., Chidambaranathan N., Jegatheesan K. 2014. Hepatoprotective effect of embilica officinalis and its silver nanoparticles against $\mathrm{CCl}_{4}$ induced hepatotoxicity in wistar albino rats. DJNB, 9: 223-235.

[6] Sotelo-Feliz J.I., Martinez-Fong D., Muriel P., Santillan R.L., Castillo D., Yahuaca P. 2002. Evaluation of the effectiveness of Rosmarinus officinalis (Lamiaceae) in the alleviation of carbon tetrachloride-induced acte hepatotoxicity in the rat. J Ethnopharmocol., 81: 145-154.

[7] MacDonald-Wickks L.K., Garg M.L. 2003. Vitamin E supplemantation in the mitigation of carbon tetrachloride induced oxidative stres in rats. Nutr Biochem., 14: 211-218.

[8] Galicia-Moreno M., Rodriguez-Rivera A., ReyesGordillo K., Segovia J., Shibayama M., Tsutsumi V., Muriel P. 2009. N-acetylcysteine prevents carbon tetrachloride-induced liver cirrhosis: role of liver transforming growth factor-beta and oxidative stress. Eur J Gastroenterol Hepatol., 21: 908-914.

[9] Dündar Y. 2001. Fitokimyasallar ve sağlıklı yaşam. Kocatepe Tıp Derg., 2: 131-8.

[10] Joshi D.D, Uniyal R.C. 2008. Different chemo types of Gokhru (Tribulus terrestris):A herb used for improving physique and physical performance. International Journal Of Gren Pharmacy. 2 (3): $158-161$.

[11] Li J.X., Shi Q., Xiong Q.B., Prasain J.K., Tezuka Y., Hareyama T., Wang Z.T., Tanaka K., Namba T., Kadota S. 1998. Tribulusamide A and B, new hepatoprotective lignanamides from the fruits of Tribulus terrestris: indications of cytoprotective activity in murine hepatocyte culture. Planta Med., 64 (7): 628-31.

[12] Liang D., Zhou Q., Gong W., Wang Y., Nie Z., He H., Li J., Wu J., Wu C., Zhang J. 2011. Studies on the antioxidant and hepatoprotective activities of polysaccharides from Talinum triangulare. Ethnopharmacol. J22, 136 (2): 316-21.

[13] Manibusan M.K., Odin M., Eastmond D.A. 2007. Postulated carbon tetrachloride mode of action: A review. J Environ Sci Heal C, 25: 185-209.

[14] Gnanaprakash K., Madhusudhana C.C., Ramkanth S., Alagusundaram M., Tiruvengadarajan V.S., Angala Parameswari S., Mohamed Saleem T.S. 2010. Aqueous extract of Flacourtia indica prevents carbon tetrachloride induced hepatotoxicity in rat. Int J Biol Sci., 6: 51-5.

[15] Ökten A. 1998. Türkiye'de karaciger sirozunun etyolojisi. Hepotolojide Güncel Gelişmeler Sempozyum Kitabı, 67s.

[16] Wang H., Wei W., Wang N.P. 2005. Melatonin ameliorates carbontetrachloride-induced hepatic fibrogenesis in rats via inhibition of oxidative stres. Life Sci., 77: 1902-1915.

[17] Gochee P.A., Johnsson J.R., Clouston A.D. 2003. Steatozis in Chronic Hepatitis C: association with increased Messenger RNA Expression of Collagen I, tumor necrosis factor-alpha and cytochrome P450 2E1. J Gastro Hepatolog.. 18: 386-392.

[18] Chin P.L., Momand J., Pfeifer G.P. 1997. In vivo evidence for binding of p53 to consensus binding sites in the $\mathrm{p} 21$ and GADD45 genes in response to ionizing radiation. Oncogene, 15: 87100.

[19] Li M., Qu W., Wang Y., Wan H., Tian C. 2002. Hypoglycemic effect of saponin from Tribulus terrestris. Zhong Yao Cai., 25 (6): 420-2. 
[20] Chu S., Qu W., Pang X., Sun B., Huang X. 2003. Effect of saponin from Tribulus terrestris on hyperlipidemia. Zhong-Yao-Cai., 26 (5): 341-4.

[21] Phillips O.A, Mathew K.T, Oriowo M.A. 2006. Antihypertensive and vasodilator effects of methanolic and aqueous extracts of Tribulus terrestris in rats. Journal of Ethnopharmacology, 104: 351-355.

[22] Tantawy W.H, Hassain L.A. 2007. Hypoglycemic and hypolipidemic effects of alcoholic extract of Tribulus alatus in streptozotocin-induced diabetic rats: A comparative study with T. terrestris (Caltrop). Indian J Exp Biol., 45: 785- 90.

[23] Grigorova S., Kashamov B., Sredkova V., Surdjiiska S., Kurtenkov A. 2008. Effect Of Tribulus terrestris Extract On Semen Quality And Serum Total Cholesterol Content In White PlymouthMini Cocks. Institute of Animal Science, Kostinbrod, Bulgaria, 24 (3-4): 139-146.

[24] Tuncer M.A, Yaymacı B, Satı L., Çaylı S., Acar G., Altuğ T., Demir R. 2009. Influence of Tribulus terrestris extract on lipid profile and endothelial structure in developing atherosclerotic lesions in the aorta of rabbits on a highcholesterol diet. Acta Histochemica, 111 (6): 488-500.

[25] Amin A., Lotfy M., Shafiullah M., Adeghate E. 2009. The Protective Effect of Tribulus terrestris in Diabetes. The New York Academy of Sciences, 1084: 391-401.

[26] Duru M., Şahin A. 2015. Farklı Taşıyıcılarla Rasyona Eklenen Demir Dikeninin (Tribulus terrestris) Yumurtac1 Tavuklarda Verim Ve Yumurta Kalitesi Üzerine Etkileri. Journal of Food and Health Science, 1 (2): 84-93

[27] Botsoglou N.A., Taitzoglou I.A., Botsoglou E., Zervos I., Kokoli A., Christaki E., Nikolaidis E., 2009. Effect of long-term dietary administration of oregano and rosemary on the antioxidant status of rat serum, liver, kidney and heart after carbon tetrachloride-induced oxidative stress. J Sci Food Agric., 89: 1397-406.

[28] Al-Assaf A.H. 2013. Preventive effect of corosolic acid on lipid profile against carbon tetrachloride induced hepatotoxic rats. Pak J Nut., 12: 748-52.

[29] Rajesh M.G., Latha M.S. 2001. Hepatoprotection by Elephantopus scaber L. in $\mathrm{CCl}_{4}$-induced liver injury. Indian J Physiol Pharmacol, 45: 481-6.

[30] Venukumar M.R., Latha M.S. 2002. Hepatoprotective effect of the methanolic extract Curculigo orchioides in $\mathrm{CCl}_{4}$ treated male rats. Indian J Pharmacol., 34: 269-75.

[31] Santra A., Chowdhury A., Ghatak S., Biswas A., Dhali G.K. 2007. Arsenic induces apoptosis in mouse liver is mitochondria dependent and is abrogated by $\mathrm{N}$-acetylcysteine. Toxicol Appl Pharmacol., 220: 146-55.

[32] Ahsan R., Islam K.M., Musaddik A., Haque E. 2009. Hepatoprotective activity of methanol extract of some medicinal plants against carbon tetrachloride induced hepatotoxicity in Albino rats. Global J Pharm. 3: 116-22.

[33] Feroz Khan Z., Asdaq S.M.B., Prasanna Kumar S.R. 2009. Effects of few Indian medicinal herbs on carbon tetrachloride induced hepatic injury in animals. International J Pharm Tech Res., 1: $579-87$. 